\title{
Medical Perioperative Management In Patient with Acute Kidney Disease
}

\author{
Caesar Ayudi1 ${ }^{1}$, Widodo ${ }^{2 *}$ \\ ${ }^{1}$ Department of Internal Medicine, Faculty of Medicine, Universitas Airlangga - Dr. Soetomo General Hospital Surabaya, \\ Indonesia. \\ ${ }^{2}$ Division of Nephrology and Hypertension, Department of Internal Medicine, Faculty of Medicine, Universitas Airlangga - \\ Dr. Soetomo General Hospital Surabaya, Indonesia.
}

\begin{abstract}
A B S T R A C T
Acute kidney disease (AKD) is the course of disease after AKI among patients of whom the renal pathophysiologic processes are ongoing. Perioperative management become an important component of the clinical practice of internists, as well as other primary care physicians and subspecialists. KDIGO Bundles states proper perioperative AKI management includes discontinuation of all nephrotic agents, ensuring volume status and perfusion pressure, considering functional hemodynamic monitoring, monitoring $\mathrm{SCr}$ and Urine Output, avoiding hyperglycemia, and considering alternatives to radiocontrast procedures. It is commonly recommended to titrate crystalloid infusion to maintain MAP $>65$ $70 \mathrm{mmHg}$, urine output $>0.5 \mathrm{cc} / \mathrm{kg} / \mathrm{h}$ and CVP 10-15 mmHg. Minimizing perioperative exposure to nephrotoxic drugs. More recent studies suggest higher glucose levels should be allowed in maintaining reasonable glycemic control with values less than $180 \mathrm{mg} / \mathrm{dL}$. However, the intraoperative use of diuretics can only be recommended for managing severe fluid overload and not for preventing AKI. Dialysis has not been shown to decrease perioperative AKI, it can treat the associated acidosis, hyperkalemia, and hypervolemia. Intraoperative hypotension is considered a risk factor for AKI after surgery. We reported a case report of AKD stage B/C with underlying Ca Cervix III B.
\end{abstract}

Keywords: Acute kidney disease, Medical, Management, Perioperative

Correspondence: Widodo

E-mail:widd22@yahoo.com

Article history: • Received 18 August $2020 \bullet$ Received in revised form 28 August $2020 \bullet$ Accepted 31 August 2020

\begin{abstract}
INTRODUCTION
Acute kidney injury (AKI) is a condition when the renal function suddenly decreased ( $>48$ hour) that leads to the increase of creatinine serum $\geq 0.3 \mathrm{mg} / \mathrm{dl}$ or $\geq 50 \%(1.5$ times than the baseline) or decrease of urine output (oliguria $<$ $0.5 \mathrm{ml} / \mathrm{KgBW} /$ hour, $>6$ hour) (Thakar, 2012). The Kidney Disease: Improving Global Outcomes (KDIGO) guideline defines AKI as abrupt decrease in kidney function over a period of $<=7$ days and CKD as abnormalities in kidney structure or function that persist for $>90$ days. The term acute kidney disease (AKD) has been proposed to define the course of disease after AKI among patients of whom the renal pathophysiologic processes are ongoing. AKD is conceptualized not as pre CKD but rather as post AKI (Chawla, et al., 2017). AKI is a serious morbidity occurring during acute care hospitalizations, which independently contributes to greater length of stay, high costs of care, and increased risk of death (Goren \& Matot, 2015). AKI during hospitalization increases the risk of progressive kidney failure and is associated with poor long-term survival. The incidence of AKI is generally observed in 5-7.5\% in all acute care hospitalizations, of all the cases of AKI during hospitalization, approximately $35-40 \%$ are related to operative settings (Thakar, 2011).
\end{abstract}

The significant increase in perioperative morbidity and mortality depends on a number of preexisting risk factors and comorbidities, the nature and timing of the operation and anesthesia. Preoperative renal insufficiency is the most important risk factor for developing acute on chronic renal failure after surgical procedure and is associated with a high mortality. Other serious complications include volume overload, hypertension, bleeding, acidosis, and electrolyte disturbances such as hyperkalemia (Kohli M, 2012).

The proper perioperative strategy is to preserve renal function to optimize the patient outcome and decrease morbidity and mortality. Perioperative optimalization on patient with renal dysfunction needs to consider the prior renal function and another condition that potentially raises the perioperative AKI risk (Jones \& Lee, 2009). They have other comorbidities, including hypertension, diabetes, peripheral vascular disease, and cardiac disease (Gross \& Prowle, 2014). Renal failure has various consequences on homeostasis that are not only restricted to water and electrolyte abnormalities, but affect many organ system, making intraoperative management of these patients especially challenging (Wagener \& Brentjens, 2010). Perioperative management of the surgical patient has become an important component of the clinical practice of internists, particularly hospitalists, as well as other primary 
care physicians \& subspecialists (Cohn, 2011).

\section{CASE REPORT}

The Patient was a 65-year-old woman, a housewife, who lives in Kedungsari Megaluh Village, Jombang, East Java. She was admitted to Dr. Soetomo General Hospital on 18th February 2019 with chief complain of vaginal bleeding.

\section{Anamnesis}

The patient was consulted by obstetrician with an increase of renal function test result. The patient complained of having massive vaginal bleeding for 2 months that leaked nearly every day and sometimes it expulsed red-blackish clot. This complain was not affected by time or activity. The patient also complained of fainting, pale, decreasing appetite and desire to drink. The patient never complained any stomach pain, stomach cramp or palpable mass in the abdomen. The patient already did check-up at Jombang General Hospital, and she was suspected of having cervical cancer. The patient was hospitalized for 4 days and was given some medications (the patient did not remember the medication) to stop the bleeding. Then, the patient's condition improved as the bleeding decreased and clot disappeared although there was still a slight bleeding. Thus, the patient was permitted to undergone outpatient treatment. However, in January the patient re-experienced massive bleeding and then she was hospitalized again for 3 days in Jombang General Hospital, and was referred to undergone outpatient treatment at Department of Obstetrics ang Gynecology of Dr. Soetomo General Hospital. In the last 2 weeks the patient complained that her urine output decreased from $2,000 \mathrm{ml} / 24$ hour to $1,500 \mathrm{ml} / 24$ hour. The patient was planned to undergone chemotherapy and radiotherapy but not yet implemented.

The patient never complained any vaginal bleeding or discharge before even after coitus. The patient said that she routinely consumed traditional herb for vaginal vitality every once a month. The Patient consumed some of pain killer or herb medications occasionally when she experienced mild illness.

The history of the patient's illness. The patient never suffers liver disease, diabetes mellitus (DM), or hypertension before. The patient Suffered pulmonic TBC 10 years ago and already undergone 6 months' therapy and declared healed. The patient never consume alcohol, or painkiller dugs routinely. The patient's family never have any history of liver disease, blood abnormality, cancer, DM and hypertension.

The history of medication. The patient was treated at Jombang General Hospital in December and January, but she did not bring any data of the last treatment. Nevertheless, according to the patient, she was given medication to stop the vaginal bleeding she experienced.

The history of labour. The patient has 4 children. The first children is 45-years-old male, the second is 40-yearsold male, the third is 36-years-old female, and he fourth is 28 -years-old male, all born with normal labour. The patient already had menopause since 5 years ago.

The social history. The patient is a housewife, she used to sell food in kindergarten (stopped 5 years ago). Before becoming sick, the patient could do activities daily, lived independently and actively attended social activity such as recitation. Nevertheless, since she got sick, the patient more likely spent her time at home because of weakness. Her husband died in 2015 because of pulmonary disease.

Physical examination obtained GCS 456, general state weak, nutritional status underweight (BMI $17.7 \mathrm{~kg}$ / $\mathrm{m} 2$ ), blood pressure $110 / 80 \mathrm{mmHg}$, pulse $94 \mathrm{x} /$ minute, respiratory rate $20 \mathrm{x} /$ minutes, axillar temperature 36.8 ${ }^{\circ} \mathrm{C}$, urine output about $1,500 \mathrm{ml} / 24$ hours. Head and neck examination acquired pale conjunctiva and no increase of JVP. Thorax examination acquired thoracic movement was symmetrical, no intercostalis retraction or supraclavicular retraction. Heart physical examination acquired S1 and S2 single sound, regular, no audible heart murmur or gallop. Pulmonary physical examination acquired vesicular breathing sound, no rhonchi or wheezing in both lungs.

Abdominal examination acquired flexible, bowel sound normal, and tympanic percussion. There was no enlargement of liver or spleen. Vaginal toucher examination acquired no active bleeding, a palpable irregular mass at the portio, uterine body normal, parametrium/adnexal normal, and no palpable mass. Extremity examination acquired warm akral, dry, oedema on all of the extremity, and no petechiae or purpura.

The laboratory findings on 15th February 2019. Hb $6.1 \mathrm{~g} / \mathrm{dl}, \mathrm{MCV} 73.1 \mathrm{fl}, \mathrm{MCH} 22.2 \mathrm{pg}, \mathrm{WBC} 7,880 / \mathrm{uL}$, neutrophil 75\%, HCT 20.1\%, PLT 523,000/uL, BUN $29 \mathrm{mg} / \mathrm{dl}$, Creatinine serum $3.5 \mathrm{mg} / \mathrm{dl}$, SGOT $22 \mathrm{U} / \mathrm{L}$, SGPT $18 \mathrm{U} / \mathrm{L}$, albumin $2.8 \mathrm{~g} / \mathrm{dl}$, blood glucose $106 \mathrm{mg} /$ dl, PPT 10.2 (9-12), APTT 27.3 (23-33), Na 134 mmol/L, potassiumm $4.4 \mathrm{mmol} / \mathrm{L}$, Chloride $97 \mathrm{mmol} / \mathrm{L}$. Laboratory findings on $1^{\text {st }}$ February 2019. Hb $7.8 \mathrm{~g} / \mathrm{dl}$, MCV 72.9 fl, MCH 22 pg, WBC 9,840/uL, neutrophil 77.7\%, HCT 25.8\%, PLT 609,000/uL, BUN 17 mg/dl, Creatinine serum $2.62 \mathrm{mg} / \mathrm{dl}$, SGOT $21 \mathrm{U} / \mathrm{L}$, SGPT $6 \mathrm{U} / \mathrm{L}$, albumin $3.1 \mathrm{~g} /$ $\mathrm{dl}$, fasting blood glucose $124 \mathrm{mg} / \mathrm{dl}, 2$ hours post prandial blood glucose $124 \mathrm{mg} / \mathrm{dl}, \mathrm{Na} 137 \mathrm{mmol} / \mathrm{L}$, potassium 5,0 mmol/L, Chloride $100 \mathrm{mmol} / \mathrm{L}, \mathrm{HbsAg}$ non-reactive. Laboratory findings on $11^{\text {th }}$ February 2019 urine analysis: pH 6.0, color: red, leukocyte +3 , nitrite negative, protein +3 , glucose negative, albumin : creatinine $150 \mathrm{mg} / \mathrm{g}$, protein : creatinine $500 \mathrm{mg} / \mathrm{g}$.

X-ray examination on $29^{\text {th }}$ January 2019 : impression : reticulogranular formation on both lungs could be a signs of metastatic process (miliary type). ECG : Sinus 100x/ minutes. Abdominal USG on 29th January 2019: Malignant mass on Cervix uteri with measurement $5.19 \times 6.49 \times 5.89$ $\mathrm{cm}$ that spread to uterine body, $1 / 3$ proximal of vagina and right-left parametrium. Severe hydronephrosis with hydroureter left-right. Cholelithiasis. There was no visible metastatic process on liver or paraaorta lympnode. Ther is no abnormalities on liver/spleen/pancreas/vesica urinary. Pathological and anatomical examination on 14th January 2019 : Invasive non-Keratinizing squamous cell carcinoma, large cell type. Consultation to Cardiology Department: obtained CRI class II (according to the increase of creatinine serum + Stable cardiac condition + low risk surgery + post functional capacity), anemia, Hypertension stadium I JNC VII, and sinus tachycardia 
because of anemia. Consultation to Urology obtained $\mathrm{Ca}$ Cervix IIIB + moderate hydronephrosis $\mathrm{D} / \mathrm{S}+\mathrm{AKI} \mathrm{dd}$ ACKD. The patient is planned on DJ stent insertion $\mathrm{D} / \mathrm{S}$.

Initial working diagnosis were Squamous Cell Carcinoma cervix III B + Anemia + Renal insufficiency + Severe Hydronephosis dextra et Sinistra + Hipoalbumin. The patient was planned bloodwork after transfusion, abdominal X-ray, Urine analysis, Calcium/phosphate, APTT/PTT, Albumin evaluation, RFT Serial (BUN/ SK) and SE, Consultation to Department of Urology for DJ Stent insertion $\mathrm{D} / \mathrm{S}$, and planning chemotherapy and radiotherapy therapy. The patient was hospitalized and was given diet therapy with high calorie intake 19,000 Kcal/ days with enough protein $(0.8-1 \mathrm{~g} / \mathrm{Kg} \mathrm{BW} /$ days $)$, fluid balance input $=$ output $+500 \mathrm{ml}$, PRC transfusion $1 \mathrm{kolf} /$ days until $\mathrm{Hb} \geq 10 \mathrm{gr} / \mathrm{dl}$. $\mathrm{NaCl} 0.9 \%$ infusion $1,000 \mathrm{ml} / 24$ hour, tranexamic acid $500 \mathrm{mg} / 12$ hour intravena, folic acid 1 tablet every 8 hour per oral. Monitor the urine production in 24 hour, vital signs, symptoms and renal function.

On the $4^{\text {th }}$ day of treatment. The patient still complained of spotting and bleeding from the vagina, but only a few and no clotting, no breathing difficulties, no fever, no nausea, vomiting or diarrhea. The physical examinations of the patient were blood pressure $115 / 75 \mathrm{mmHg}$, pulse $80 \mathrm{x} /$ minute, temperature $36.7^{\circ} \mathrm{C}$, respiratory rate $20 \mathrm{x} /$ minutes, urine production $1,800 \mathrm{ml} / 24$ hour. Abdominal $\mathrm{x}$-ray on $2^{\text {nd }}$ February 2019: no signs of metastatic on bone that visualized, spondylosis lumbar. Laboratory findings on $21^{\text {st }}$ February 2019: TIBC $93 \mathrm{ug} / \mathrm{dL}$, SI $16 \mathrm{ug} / \mathrm{dL}$, Na $142 \mathrm{mmol} / \mathrm{l}, \mathrm{K} 4.5 \mathrm{mmol} / \mathrm{l}, \mathrm{Cl} 105 \mathrm{mmol} / \mathrm{l}$, BUN $40 \mathrm{mg} /$ dl, Creatinine Serum $3.42 \mathrm{mg} / \mathrm{dl}$, P $3 \mathrm{mg} / \mathrm{dL}$, Ca $7.4 \mathrm{mg} /$ dL, Hb 10.4 gr/dL, HCT 32.3\%, Plt 392x103/uL. BGA: pH 7.38, $\mathrm{pCO}_{2} 35 \mathrm{mmHg}, \mathrm{PO}_{2} 21 \mathrm{mmHg}, \mathrm{BE}-4.4 \mathrm{mmol} / 1, \mathrm{SO}_{2}$ $33 \%, \mathrm{HCO}_{3} 20.7 \mathrm{mmol} / \mathrm{l}$. Urinalysis: $\mathrm{pH} 6.5$, leukocyte +2 , Nitrite -, Protein +1 , erythrocyte +2 , albumin : creatinine $\geq$ $300 \mathrm{mg} / \mathrm{g}$, Protein : creatinine $\geq 1500 \mathrm{mg} / \mathrm{g}$.

On the 6 th day of treatment. The patient said that the bleeding stopped, but still complained about being fainted and nausea. The physical examinations were blood pressure $110 / 70 \mathrm{mmHg}$, pulse $82 \mathrm{x} /$ minute, temperature $36.4{ }^{\circ} \mathrm{C}$, respiratory rate $20 \mathrm{x} /$ minutes, urine production $1,700 \mathrm{ml} / 24$ hour. Laboratory findings on $23^{\text {rd }}$ February 2019: Na 139 $\mathrm{mmol} / \mathrm{l}, \mathrm{K} 4.1 \mathrm{mmol} / \mathrm{l}, \mathrm{Cl} 107 \mathrm{mmol} / \mathrm{l}$. BGA pH 7.38, $\mathrm{pCO}_{2} 26 \mathrm{mmHg}, \mathrm{pO}_{2} 72 \mathrm{mmHg}, \mathrm{BE}-9.7 \mathrm{mmol} / 1, \mathrm{SO}_{2}$ $94 \%, \mathrm{HCO}_{3} 15.4 \mathrm{mmol} / \mathrm{l}$. BUN $26 \mathrm{mg} / \mathrm{dL}$, SK $4.11 \mathrm{mg} /$ dL. The thorax imaging findings on $24^{\text {th }}$ February 2019: reticulogranular pattern on both lung fields, suggesting DD : Metastatic process/pneumonia interstitial, heart in normal finding, there was no metastatic process on bone that visualized. The patient was given added treatment: Natrium bicarbonate infusion $25 \mathrm{meq} / 12$ hour intravenous.

On the $8^{\text {th }}$ day of treatment. The patient did not complain vaginal bleeding anymore. Appetite and desire to drink were adequate. The physical examinations were blood pressure $110 / 75 \mathrm{mmHg}$, pulse $82 \mathrm{x} /$ minutes, temperature $36.4^{\circ} \mathrm{C}$, respiratory rate $18 \mathrm{x} /$ minutes, urine production $1,700 \mathrm{ml} / 24$ hour. Laboratory findings 25 th February 2019 : $\mathrm{pH} 7.35, \mathrm{pCO}_{2} 27 \mathrm{mmHg}, \mathrm{PO}_{2} 92 \mathrm{mmHg}, \mathrm{BE}-11.8 \mathrm{mmol} / \mathrm{l}$, $\mathrm{SO}_{2} 94 \%, \mathrm{HCO}_{3} 13.8 \mathrm{mmol} / 1$.

On the $10^{\text {th }}$ day of treatment. The patient complained slight cough but no vaginal bleeding anymore. The physical examinations were blood pressure $120 / 75 \mathrm{mmHg}$, pulse $96 \mathrm{x} /$ minutes, temperature $37.2^{\circ} \mathrm{C}$, respiratory rate $20 \mathrm{x} /$ minutes. Laboratory findings: $\mathrm{Na} 132 \mathrm{mmol} / \mathrm{l}$, potassium $3.3 \mathrm{mmol} / \mathrm{l}$, chloride $107 \mathrm{mmol} / \mathrm{l}$, random blood glucose $124 \mathrm{mg} / \mathrm{dl}$. Blood gas analysis: $\mathrm{pH} 7.35, \mathrm{pCO}_{2} 25 \mathrm{mmHg}$, $\mathrm{PO}_{2} 93 \mathrm{mmHg}, \mathrm{BE}-7.8 \mathrm{mmol} / \mathrm{l}, \mathrm{SO}_{2} 94 \%, \mathrm{HCO}_{3} 17.8$ $\mathrm{mmol} / \mathrm{l}$. The patient was given treatment nebulization $\mathrm{NaCl}$ $0.9 \% 2 \mathrm{ml}$, chest physiotherapy, chough exercise, esilgan peroral $2 \mathrm{mg}$ on the night. The patient then was inserted by DJ Stent sinistra (SAB technique of anesthesia) on indication of severe hydronephrosis sinistra. The patient's urine production was $1,700 \mathrm{ml} / 24$ hour ( $70 \mathrm{ml} /$ hour $)$.

On the $11^{\text {th }}$ day of treatment. The patient complained hard to excrete her sputum, nausea and her urine was red coloured. There were no complains of vaginal bleeding, vomiting, difficulties to breath, fever or diarrhea. The physical examinations were blood pressure 120/70 $\mathrm{mmHg}$, pulse $84 \mathrm{x} /$ minutes, temperature $36.7^{\circ} \mathrm{C}$, respiratory rate $20 \mathrm{x} /$ minutes, urine production $1,600 \mathrm{ml} / 24$ hour. The patient was diagnosed with AKD, anemia, compensated metabolic acidosis, hipoalbumin, Severe HN bilateral post DJ stent sinistra insertion, Ca Cervix IIIB. Dietary therapy High Calorie Enough Protein Low Salt 1,900 $\mathrm{Kcal} /$ Day. Fluid balance input $=$ output $+500 \mathrm{ml}, \mathrm{NaCl} 0.9 \%$ infusion $1,000 \mathrm{ml} / 24$ hour intravenous drip, ceftriaxone injection 1 gram every 12 hour intravenous, tranexamic acid injection $500 \mathrm{mg} / 8$ hour intravenous, folic acid per oral 1 tablet every 8 hour. On the $13^{\text {th }}$ day of treatment, the patient was planned to be discharged and get outpatient treatment at Department of Obstetrics and Gynecology, Urology and Nephrology, respectively. On $4^{\text {th }}$ April 2019 for laboratory evaluation post DJ stent placement: BUN 19 $\mathrm{mg} / \mathrm{dl}$, Creatinine serum $1.5 \mathrm{mg} / \mathrm{dl}$. CT scan thorax - axial reformatted coronal and sagittal without and with contrast: multiple nodule in right pulmonary superior lobes-anterior segment and left pulmonary inferior lobes-medial basal segment.

\section{DISCUSSION}

The patient was consulted by Department of obstetrics and Gynaecology. The patient was Mrs. W, 65-yearsold female treated in Merak ward with diagnosis $\mathrm{Ca}$ Cervix III B + Anemia + increase of RFT + Severe hydronephrosis bilateral and hydroureter bilateral. The patient was consulted to Department of Internal Medicine with elevated RFT. From examination obtained decrease of urine production 2 weeks prior from $2.000 \mathrm{ml} / 24$ hour to $1,500 \mathrm{ml} / 24$ hour. According to the laboratory findings on $1^{\text {st }}$ February 2019, BUN $17 \mathrm{mg} / \mathrm{dl}$, creatinine $2.62 \mathrm{mg} /$ $\mathrm{dl}$ and also on $15^{\text {th }}$ February 2019, BUN $29 \mathrm{mg} / \mathrm{dl}$, and creatinine $3.5 \mathrm{mg} / \mathrm{dl}$. Thus, we needed to evaluate further from the data we found.

We diagnosed the patient with AKD stage B/C. The patient also had adeno Ca Cervix stage III B, supported by abdominal USG on $29^{\text {th }}$ January 2019.

The term AKD has been proposed to define the course of disease after AKI among patients of whom the renal pathophysiologic processes are ongoing. AKD is defined as a condition after an AKI initiating event. AKD that persists 
beyond 90 days is considered to be CKD (Chawla, et al., 2017). According to KDIGO guideline, functional criteriaAKD are GFR $<60 \mathrm{~mL} / \mathrm{min} / 1.73 \mathrm{~m} 2$ for $<3$ months or decrease in GFR by $>=35 \%$ or increase in serum creatinine (SCr) by $>50 \%$ for $<3$ months and structural criteria are kidney damage for $<3$ months. Recommendations for AKD staging: Stage 0-A; Absence of criteria for B or C: Stage 0 -B; Continued evidence of ongoing injury, repair and/ or regeneration or indicators of loss of renal glomerular or tubular reserve: Stage 0-C; Serum creatinine level, 1.5 times baseline but not back to baseline levels: Stage $B / C$; Serum creatinine level, 1.5 times baseline but not back to baseline levels and continued evidence of ongoing injury, repair and/or regeneration: Stage 1; serum creatinine level 1.5-1.9 times baseline: Stage 2; serum creatinine level 2.02.9 times baseline: Stage 3; serum creatinine level 3.0 times baseline or increase serum creatinine to $>353.6 \mu \mathrm{mol} / \mathrm{L}$ or ongoing need for renal replacement therapy (Levey \& Scwartz, 2013).

In the patient we obtained risk factor susceptibility which was malignancy on cervix, cause of AKI was postrenal (extrinsic upper urinary tract) which was malignancy on cervix. The patient has another risk factor for AKD such as low intake (consumption of food and fluid), which caused dehydration or fluid deficit.

The patient needed to be evaluated about the risk factor and cause of AKD for establishing the right diagnosis and therapy (Borthwick \& Ferguson, 2012). Risk factor of AKI according to exposure and susceptibility. AKI is categorized as AKI pre-renal, renal/intrinsic and post-renal. Risk factor of AKI according to exposure are: sepsis, critical illness, circulatory shock, burn wound, trauma, large surgery, heart surgery nephrotoxic drugs, and radiocontrast agent and plant/animal toxins. Risk factor of AKI according to susceptibility are: dehydration/deficit of fluid, elderly, women, Negro, CKD, chronic disease (heart, lung, liver), diabetes mellitus, cancer and anemia. The pre renal cause of AKI are: decreased kidney perfusion. The renal cause of AKI are: acute glomerulonephritis, vasculitis, interstitial nephritis, thrombotic microangiopathy. The post renal cause of AKI are: urinary tract obstruction (Kidney Disease: Improving Global Outcomes (KDIGO) Acute Kidney Injury WorkGroup, 2012).

The patient was 60 years old (risk factor: if $>56$ years old), intraperitoneal surgery and renal insufficiency. There were three risk factors which caused the patient to be categorized as class II for AKI incidence.

Stage IIIB Cervix Adenocarcinoma patient with bilateral severe hydronephrosis as complication will undergo an operative procedure called DJ stent insertion for both sides, performed by Department of Urology. Prior to the procedure, perioperative management has to be conducted thoroughly, which includes an anticipation of the occurrence of AKI (Hobson, et al., 2017). There are risk factors to predict risk of AKI: age $>=56$ years, BMI $>32$, male sex, active CHF, ascites, hypertension, emergency surgery, intraperitoneal surgery, COPD, renal insufficiency (mild or moderate; preoperative serum creatinine $>1.2$ $\mathrm{mg} / \mathrm{dL}), \mathrm{DM}$ on oral or insulin therapy. Preoperative risk class: Class 1 (0-2 risk factors) : AKI incidence -
Derivation cohort $0.2 \%$, Validation cohort $0.2 \%$. Class II (3-4 risk factors) : AKI incidence - Derivation cohort $0.8 \%$, Validation cohort $0.8 \%$. Class III (4 risk factors) : AKI incidence - Derivation cohort 1.8\%, Validation cohort $2.0 \%$. Class IV (5 risk factors) : AKI incidence Derivation cohort 3.3\%, Validation cohort 3.6\%. Class $\mathrm{V}(>=6$ risk factors) : AKI incidence - Derivation cohort 8.9\%, Validation cohort 9.5\% (Gross \& Prowle, 2016).

The patient was planned to undergo an elective procedure, DJ stent implantation indication for the patient was the existing severe bilateral hydronephrosis which was caused by cervix cancer. The implantation of DJ stent was done temporarily until the definitive treatment of cervix cancer using chemotherapy and radiotherapy were done. The patient's condition prior to the procedure was stable; no hypo/hypertension, euvolemic, no electrolyte imbalance, no abnormality in blood gas analysis test, and good level of hemoglobin and platelets.

DJ stent implantation indication are urgent and relative. Urgent indications are due to obstructive pyelonephritis and acute renal colic. Relative indication include the small size $(<2 \mathrm{~mm})$, pregnancy, prolong impaction of the stone, history of UTI, and severe hydronephrosis (Miyaoka \& Monga, 2009). Stent implantation may work as a temporary treatment until the definitive or permanent treatment depends on the patient's (Tailly \& Denstedt, 2016). Urinary diversion operations are complicated procedures, usually performed because of urinary tract malignancies or other lower abdominal/pelvic malignancies (cervical, rectal), postoperative recovery is good and steady, also the patient can receive radical radiotherapy better (Johnson B, 2011; Jiang, et al., 2016).

As a part of the DJ stent implantation procedure, subarachnoid block anesthesia was done at level of lumbar vertebrae 3-4, using combination of local anesthesia of Lidodex $5 \%$ and adrenaline $0.1 \mathrm{mg}$. Blood pressure of the patient pre-anesthesia was $140 / 80 \mathrm{mmHg}$, duration of operation and anaesthesia systolic blood pressure 90-140 $\mathrm{mmHg}$, diastolic blood pressure between 60-80 $\mathrm{mmHg}$, and MAP was 70-112 mmHg. During operation, the patient was given $250 \mathrm{ml}$ of $\mathrm{NaCl} 0.9 \%$ without colloid or blood products, urine output produced was $300 \mathrm{ml} / 2$ hours.

Neuraxial block (spinal anesthesia) has its place in patients with CRF. It is administered whenever there is an indication because it is logical choice as it avoids the effects of muscle relaxants, narcotics, and potent volatile anesthetics. Sympathetic blockade is an important consideration when utilizing epidural or spinal anesthesia. A high level of blockade can result in significant drop in blood pressure and GFR. Careful preoperative fluid loading will help offset the degree of hypotension (Zura \& Sakic, 2013).

Important considerations in patient with insufficiency renal are use of anesthetic agents and sedatives in perioperative period. Many drugs commonly used during anesthesia are dependent to some degree on renal excretion for elimination and this must be taken into consideration when planning an anesthetic for a patient with renal dysfunction. Propofol and isoflurane are well tolerated and widely used anesthetic agents, although induction doses may need to be reduced in a patient with renal insufficiency 
(Kohli M, 2012). Some narcotics agent including morphine and meperidine should be used judiciously if at all as they have active metabolites and may have prolonged activity in renal dysfunction (Wagener \& Brentjens, 2010).

There were hematuria and discomfort in the flank and suprapubic area as the complication for the implantation of DJ stent, yet these complications only lasted for several days and her condition got better afterwards.

Major complications with ureteral stents are recurrent infection, displacement, and blockage by encrustation. Other complications are storage urinary symptoms like increased urgency and frequency of urination, hematuria, discomfort in flank, suprapubic, and groin region (Choudhury, et al., 2017). The late complications (10$20 \%$ of patients) are metabolic disorders, stoma problems (stenosis or hernia), pyelonephritis and calculi (Gupta, et al., 2017).

There was no history of abnormal vaginal bleeding, vomiting, or diarrhea found in the patient. From the physical examination, the blood pressure was $120 / 75 \mathrm{mmHg}$, pulse $96 \mathrm{x} / \mathrm{min}$, respiratory rate $20 \mathrm{x} / \mathrm{min}$, temperature 37.2 ocelcius and urine output was $1,700 \mathrm{cc} / 24$ hour. From the laboratory, $\mathrm{Hb} 10.3 \mathrm{gr} / \mathrm{dL}$, HCT $28.4 \%$, plt 348x103/uL, Natrium $132 \mathrm{mmol} / \mathrm{l}$, Potassium $3.3 \mathrm{mmol} / \mathrm{l}$, Chloride 107 $\mathrm{mmol} / \mathrm{l}$, and random blood glucose level at $124 \mathrm{mg} / \mathrm{dl}$, blood gas analysis showed pH 7.35, pCO2 $25 \mathrm{mmHg}, \mathrm{PO} 2$ $93 \mathrm{mmHg}, \mathrm{BE}-7.8 \mathrm{mmol} / \mathrm{l}, \mathrm{SO} 2$ 94\%, HCO3 $17.8 \mathrm{mmol} / \mathrm{l}$. The patient was not given nephrotoxic agents.

KDIGO Bundles states proper perioperative AKI management includes discontinuation of all nephrotic agents, ensuring volume status and perfusion pressure, considering functional hemodynamic monitoring, monitoring SCr (Serum Creatinine) and UO (Urine Output), avoiding hyperglycemia, and considering alternatives to radiocontrast procedures (Ramagnoli, et al., 2018). The major goals of preoperative management are to ensure euvolemia, adequately control blood pressure, correct hyperkalemia and acidosis, minimize bleeding tendency in uremic patients, and avoid nephrotoxic agents (Schaffer \& Stefan, 2011).

Perioperative management in AKI patients includes both non-pharmacological and pharmacological therapy. Non-pharmacological approach includes intravascular volume expansion, maintenance of renal blood flow and renal perfusion pressure, avoidance of nephrotoxic agents, strict glycemic control, and appropriate management of post-operative complications. Hence the pharmacological strategies are as follows; agents such as vasodilator, diuretic, natriuretic peptides, and antioxidant (Webb \& Allen, 2008).

The patient's vital signs and hemodynamic status were stable: BP 120/75 $\mathrm{mmHg}$, pulse 96x/min, respiratory rate $20 \mathrm{x} / \mathrm{min}$, temperature 37.2 ocelcius, urine output of 1700 $\mathrm{cc} / 24$ hour, and MAP of $90 \mathrm{mmHg}$.

First non-pharmacological approach is intravascular volume expansion. Volume status needs to be optimized before surgery to assure an adequate kidney perfusion and avoid renal ischemic insult. For the patients who are not on dialysis, judicious use of diuretics and hydration as appropriate can achieve euvolemia. Maintenance of euvolemia is the goal in the perioperative, and for fluid management, crystalloid are used. It is commonly recommended to titrate crystalloid infusion to maintain MAP $>65-70 \mathrm{mmHg}$, urine output $>0.5 \mathrm{cc} / \mathrm{kg} / \mathrm{h}$ and CVP 10-15 mmHg (Schaffer \& Stefan, 2011).

A liter of normal saline was given to the patient for 24 hours intravenously. The patient did not experience any nausea, vomiting, or diarrhea. The patient's oral intake was good with a urine output of $1,700 \mathrm{cc} / 24$ hours.

Perioperative fluid therapy is aimed to maintain intravascular volume and allow tissue perfusion. Crystalloid solutions include normal saline $(0.9 \%)$ or balanced solutions (Ringer's lactate, PlasmaLyte, etc.) (Zarbock, et al., 2018). Traditionally, normal saline was the preferred intravenous fluid for patients with renal failure as it contains no potassium (Wagener \& Brentjens, 2010). While these data/novel cutoffs need to be further validated, it remains to be seen if $0.3 \mathrm{~mL} / \mathrm{kg} / \mathrm{h}$ is a better threshold for the prediction of postoperative AKI and other adverse outcomes (Zarbock, et al., 2018).

Regiments of therapy were 1 gram of ceftriaxone and $50 \mathrm{mg}$ of ranitidine every 12 hours intravenously, with a supplement of folic acid tablet every 8 hours. Drugs which were commonly used during perioperative such as NSAIDs, ACE-inhibitor, ARB, Ca-Channel blockers or radiocontrast agent were not given to the patient as they could deteriorate the patient's renal conditions. Antibiotic, in this case aminoglycoside, was carefully not chosen as it is also a nephrotoxic agent.

Minimizing perioperative exposure to nephrotoxic drugs is crucial in the prevention of ARF (Webb \& Allen, 2008). Approach to drug managements in patients with AKD are individualized risk; adjust renally excreted medications, avoid or withdraw nephrotoxic medications; withdraw drugs with active metabolites nephrotoxic agents which are often used during perioperative such as NSAID, ACE-I, ARB and radiocontrast agent can deteriorate renal function. Discontinuation ACE inhibitors on the morning of surgery, and ARBs at least $24 \mathrm{~h}$ before surgery if possible, due to their longer half-life (Whinney, 2012). NSAIDs can also cause interstitial nephritis and their association with the development of AKI (Gross \& Prowle, 2014).

Patient's blood glucose level was at the optimal level (124 mg/dl) during pre-operative. Tight glycemic control and improved outcomes in an intensive therapy unit setting, with a $41 \%$ reduction in AKI requiring RRT (Calvert \& Shaw, 2012). They show a significant reduction of patients with peak creatinine greater than $2.5 \mathrm{mg} / \mathrm{dL}$, blood urea nitrogen greater than $54 \mathrm{mg} / \mathrm{dL}$, and those requiring dialysis by controlling glucose aggressively (goals 80 $110 \mathrm{mg} / \mathrm{dL}$ ) with an insulin infusion protocol. More recent studies suggest higher glucose levels should be allowed in maintaining reasonable glycemic control with values less than $180 \mathrm{mg} / \mathrm{dL}$ in perioperative critically ill patients (Josephs \& Thakar, 2009).

We did not administer any vasopressor agent or diuretic because the patient's hemodynamic status was stable with good urine output of $1,700 \mathrm{ml} / 24$ hour and there was no sign or symptom of fluid overload in patient.

Pharmacological therapy includes the use of 
vasopressors. The benefit of vasopressor used in the setting of AKI is maintenance of renal perfusion pressure within autoregulatory limits. The current KDIGO guidelines state that the evidence so far does not support the use of one vasoactive agent over another (Goren \& Matot, 2015). In the setting of acute renal dysfunction, diuretics increase urine output by decreasing tubular reabsorption through several mechanisms (Webb \& Allen, 2008). However, the intraoperative use of diuretics can only be recommended for managing severe fluid overload and not for preventing AKI (Zarbock, et al., 2018). Diuretics are typically withheld on the morning of surgery due to concerns for volume depletion and electrolyte disruption (Whinney, 2012).

In earlier laboratory findings, (15th February 2019), the patient was found to be anemic, HCT $20.1 \%$, and PLT 523,000/uL. A 1 pack/day PRC transfusion was then done prior to the procedure, with the latest laboratory findings were $\mathrm{Hb} 10.3 \mathrm{gr} / \mathrm{dL}$, HCT $28.4 \%$ and plt 348x103/uL.

Preoperative anaemia and early postoperative decrements of haemoglobin are associated with AKI. Therefore, it is advisable to optimize the patients' preoperative hemoglobin status as suggested by the recent 'patient blood management' protocol, while using measures during surgery to reduce blood loss and avoid unnecessary PRC transfusion (Goren \& Matot, 2015). Management considers hemoglobin level of approximately $10 \mathrm{~g} / \mathrm{dl}$ and avoid severe anemia episodes (Domi, et al., 2016). Since the anemia is chronic, it is usually well-tolerated and most patients with hematocrit levels of $20-24 \%$ tolerate even major procedures without the need for preoperative transfusion (Kohli M, 2012).

NAC was not given to the patient as it shows lack of evidence to benefit of renal protective function even during perioperative period. Recent trials in the perioperative and ICU settings have shown a lack of renal protective benefit of NAC (Webb \& Allen, 2008). The role of N-acetylcysteine, an antioxidant most commonly used to enhance formation of glutathione after paracetamol overdose, has not been shown to confer any protective benefits in the perioperative period (Calvert \& Shaw,2012).

The patient did not undergo preoperative dialysis as there was no sign of overload syndrome, severe metabolic acidosis or hyperkalemia, or in oliguric/anuric condition.

Dialysis has not been shown to decrease perioperative AKI, however, it can treat the associated acidosis, hyperkalemia, and hypervolemia that may otherwise be associated with poor outcomes (Josephs \& Thakar, 2009). In severe AKI, especially in case of fluid accumulation in hemodynamically unstable anuric patients, RRT is the only supportive measure (Ramagnoli, et al., 2018). In general, dialysis should be provided on the day before the procedure.

Risks associated with the RRT procedure include hypotension, arrhythmia, membrane incompatibility, complication of vascular access, and anticoagulant administration. RRT may compromise recovery of renal function and increase the progression of CKD (Kidney Disease: Improving Global Outcomes (KDIGO) Acute Kidney Injury WorkGroup, 2012).

Electrolyte imbalance was not found in the patient, with electrolyte laboratory findings found all was normal $(\mathrm{Na}$
$132 \mathrm{mmol} / 1$, K $3.3 \mathrm{mmol} / \mathrm{l}, \mathrm{Cl} 107 \mathrm{mmol} / \mathrm{l})$. Hyperkalemia is one of the most important morbid complications in the perioperative period. A perioperative ECG should be ordered to assess the physiological effect of the hyperkalemia although ECG changes may be seen only when the potassium concentration exceeds $6.0-6.5 \mathrm{mEq} / \mathrm{L}$. In patients undergoing elective surgery, the preoperative potassium should be reduced to less than $5.0 \mathrm{mEq} / \mathrm{L}$ (Kohli M, 2012).

Blood gas analysis showed metabolic acidosis with a pH 7.38, pCO2 $26 \mathrm{mmHg}, \mathrm{pO} 292 \mathrm{mmHg}, \mathrm{BE}-9.7$ $\mathrm{mmol} / \mathrm{l}, \mathrm{SO} 294 \%$, and HCO3 $15.4 \mathrm{mmol} / \mathrm{l}$. The patient's volume status was then evaluated for a few days because of prior history of low intake and sodium bicarbonate was administered, 25 Meq every 12 hours via intravenous drip. There was an improvement of preoperative BGA study, with the $\mathrm{BE}$ of $-7.8 \mathrm{mmol} / \mathrm{l}$. Patients with $\mathrm{CKD}$ are prone to metabolic acidosis. The impairment of renal function makes it difficult to buffer a large acid load. The preoperative bicarbonate level should be greater than $18 \mathrm{mEq} / \mathrm{L}$. Bicarbonate administration with either oral replacement or intravenous infusion can raise the level without leading to significant volume expansion from the sodium load (Kohli M, 2012).

There was no history of hypertension. The patient was found to be normotensive, prior, during, and after the procedure. Preoperative optimization can be accomplished by dialysis and ultrafiltration. Management of anxiety and continuation of most antihypertensive agents through the operative day can help control blood pressure. Preoperative excessive fluid removal, $\mathrm{CHF}$, autonomic dysfunction, operative blood loss and the perioperative use of anesthetics and antihypertensive agents are important causes of hypotension (Kohli M, 2012). Intraoperative hypotension is considered a risk factor for AKI after surgery, and hypotension or hypertension during surgery is correlated with perioperative cardiac events (Schaffer \& Stefan, 2011).

The patient was underweight with the BMI of $17.7 \mathrm{~kg} /$ $\mathrm{m} 2$. The patient's oral intake was still good, despite being given a high calorie intake of $1,900 \mathrm{kkal} / \mathrm{day}$, with protein of $0.8-1 \mathrm{~g} / \mathrm{kg} \mathrm{BB} /$ day. Poor wound healing and infections can complicate postoperative course in malnourished patients. Patients with renal insufficiency who receive perioperative nutritional support have a lower mortality. Patients with renal insufficiency undergoing surgery receive enteral or parenteral nutrition if oral intake cannot be resumed soon after major surgery (Kohli M, 2012).

The patient's preoperative RFT was BUN $26 \mathrm{mg} / \mathrm{dL}$ and creatinine of $4.11 \mathrm{mg} / \mathrm{dL}$. However, this condition was expected to improve with DJ insertion procedure and holistic approach for the cervical cancer, through chemoradiotherapy. Postoperative laboratory was BUN $19 \mathrm{mg}$ / $\mathrm{dl}, \mathrm{Cr}$ serum $1.5 \mathrm{mg} / \mathrm{dl}$. Preoperative renal dysfunction is the strongest predictor for postoperative renal failure. The mortality and morbidity rates increase to $20 \%$ and $31 \%$ for patients with a creatinine $>3 \mathrm{mg} / \mathrm{dL}$. The risk of postoperative complications such as sepsis, cardiac arrest, bleeding, and respiratory complications is also higher in patients with a creatinine $>3 \mathrm{mg} / \mathrm{dL}$ (Schaffer \& Stefan, 2011). Non-cardiac perioperative AKI is an independent 
predictor of mortality as high as $26.4 \%$ with a comparison of $2.5 \%$ in patients without AKI. Even small changes in $\mathrm{SCr}$ correlate with a significant increase in the risk of death. Patients with SCr increases of 0.3 to $0.4 \mathrm{mg} / \mathrm{dL}$ had a $70 \%$ increase in the risk for death compared with patients with little or no change in SCr (Jones \& Lee, 2009). In the long term, AKI is associated with increased risk of re-admissions, risk of incident and progressive CKD, and poor long-term survival (Thakar,2012).

AKD outcome for the patient wascategorized as recovery part. The laboratory evaluation post DJ stent implantation showed BUN of $19 \mathrm{mg} / \mathrm{dl}$, creatinine of $1.5 \mathrm{mg} / \mathrm{dl}$, and urine output of $2,000 \mathrm{ml} /$ day. The renal prognosis was categorized as good, which was evaluated from the improvement of renal function and the increasing of the urine production post-implantation. Nevertheless, the prognosis for $\mathrm{Ca}$ Cervix in the patient was poor because malignancy had spread in pulmonary. Outcomes of AKD include recovery, recurrence of AKI, progression of AKD and/or death. AKD that persists beyond 90 days is considered to be CKD. Recovery is defined as a reduction in peak AKI stage and can be further refined by changes in serum creatinine level, glomerular filtration rate, biomarkers of injury or repair and/or return of renal reserve. The prognosis of patients with cancer progression that results in upper urinary tract obstruction is poor. Unfavorable prognostic factors of overall survival are no treatment after indwelling retrograde ureteral stent placement and a serum creatinine before indwelling retrograde ureteral stent placement of $1.2 \mathrm{mg} / \mathrm{dl}$ or greater (Chawla, et al., 2017).

\section{CONCLUSION}

The patient was Mrs. W, 65-years-old female with the diagnosis of $\mathrm{AKD}$ stage $\mathrm{B} / \mathrm{C}+\mathrm{Ca}$ Cervix III $\mathrm{B}$ with pulmonary metastasis + anaemia + severe hydronephrosis bilateral and hydroureter bilateral. In the patient, we obtained risk factor susceptibility was malignancy on cervix, while the cause of AKI was post-renal cause and pre renal. In addition to low intake (which caused dehydration or fluid deficit) and woman. The patient underwent an elective procedure, DJ stent insertion related to bilateral severe hydronephrosis. The patient's condition prior to procedure was stable. The implantation of the DJ stent was done temporarily until chemotherapy and radiotherapy are done. Subarachnoid block anesthesia was done at the level of lumbar vertebrae 3-4, using Lidodex 5\% and adrenaline $0.1 \mathrm{mg}$. Pre-anesthesia, duration, and post operation blood pressure of the patient were stable. There were hematuria and discomfort in the flank and suprapubic area as the complication for the implantation of DJ stent. A liter of normal saline was given to the patient for 24 hours intravenously. Regiments of therapy were ceftriaxone, ranitidine with a supplement of folic acid. Drugs which were commonly used during perioperative such as NSAIDs, ACE-inhibitor, ARB, Ca-Channel blockers or radiocontrast agent were not given. The patient's blood glucose level was at the optimal level during pre-operative. We did not administer any vasopressor agent nor diuretic. A 1 pack/day PRC transfusion was then done prior to procedure. The patient did not undergo preoperative dialysis. AKD outcome for the patient was categorized as recovery part. The renal prognosis was categorized as good, but prognosis for Ca Cervix was poor.

\section{CONFLICT OF INTEREST}

The author declare there is no conflict of interest of this study.

\section{REFERENCES}

Borthwick E \& Ferguson A, 2012 Perioperative Acute Kidney Injury : Risk Factors, Recognition, Management and Outcomes. British Medical Journal, 341:85-91.

Calvert S \& Shaw A, 2012. Perioperative Acute Kidney Injury. Perioperative Medical Journal, 1(6):1-11.

Chawla L, Bellomo R, Bihorac A, Goldstein S, Siew E, Bagshaw S, Bittleman D, Cruz D, Endre Z, Fitzgerald R, Forni L, Kane-Gill S Hoste E, Koyner J, Liu K, Macedo E, Mehta R, Murray P, Nadim M, Osterman M, Palvsky P, Pannu N, Rosner M, Wald R, Zarbock A, Ronco C \& Kellum J, 2017. Acute Kidney Disease and Renal Recovery: Consensus Report of The Acute Disease Quality Initiative (ADQI) 16 Workgroup, viewed 25 April 2019, www.nature.com/nrneph

Choudhury S, Jain P \& Pal D, 2017. Role of Urinary Diversion in Optimization of Patients of Advanced Cervical Cancer with Obstructive Uropathy. Sch.J.App.Med.Sci, 5(7C):2679-2684.

Cohn S, 2011, Role of the Medical Consultant, in Cohn S, Perioperative Medicine, Springer, London, pp.3-11.

Domi R, Huti G, Sula H, Baftiu N, Kaci M, Bodeci A \& Pesha A, 2016. From Preexisting Renal Failure to Perioperative Renal Protection. Anesth Pain Med, 6(3):1-6.

Goren O \& Matot I, 2015. Perioperative Acute Kidney Injury. British Journal of Anesthesia, 115(52):ii3-ii14.

Gross J \& Prowle J, 2015. Perioperative Acute Kidney Injury. British Journal of Anesthesia, 15(4):213-218.

Gupta S, Maurya A \& Pal D, 2017. Complications of Long Term Indwelling Double J Stent and Their Management: A Single Centre Experience. Sch.J.App.Med.Sci, 5(8D):3304-3308.

Hobson C, Ruchl R \& Blhorac A, 2017. Perioperative Acute Kidney Injury: Risk Factors and Predictive Strategies. Crit Care Clin, 33(2):379-396.

Jiang C, Fu Q, Li Z, Lv J, Qiu F, Zhong Y, Liu W, Huang Y \& Wang Y, 2016. Analysis of Treatment Strategy for Patients with Obstructive Renal Failure Caused by Advanced Cervical Carcinoma After the Failure of Retrograde Ureteral Stent Placement. Int J Clin Exp Med, 9(6):11706-11714.

Johnson B, 2011, Urologic Surgery, in Cohn S, Perioperative Medicine, Springer, London, pp.145-150.

Jones D \& Lee H, 2009. Surgery in the Patient with Renal Dysfunction. Anesthesiology clin, 27:739-749.

Josephs S \& Thakar C, 2009. Perioperative Risk Assessment, Prevention and Treatment of Acute Kidney Injury. International Anesthesiology Clinics, 47(4):89-105. 
Kidney Diasease Improving Global Outcomes (KDIGO) Acute Kidney Injury Work Group. KDIGO Clinical Practice Guideline for Acute Kidney Injury. Kidney Inter., Suppl. 2012;2: 1-138.

Kohli M, 2012, Renal Disease and Electrolyte Management, in Grant P \& Jaffer A, Perioperative Medicine : Medical Consultation and Co-Management, Willey-BlackWell, New Jersey, pp.185-199.

Levey A \& Schwartz W, 2013. Definition and Classification of Kidney Diseases. Am J Kidney Dis, 61(5):686-688.

Miyaoka R \& Monga M, 2009. Ureteral Stent Discomfort : Etiology and Management. Indian J Urol, 25:455-460.

Romagnoli S, Ricci Z \& Ronco C, 2018. Perioperative Acute Kidney Injury : Prevention, Early Recognition and Supportive Measures. Nephron Clinical Practice, 140:105110.

Stefan M \& Schaffer A, 2011, Chronic Kidney Disease, in Cohn S, Perioperative Medicine, Springer, London, pp.303314.

Tailly T \& Denstedt JD, 2016, Fundamentals of Urinary Tract, in Kavoussi LR, Partin AW, Peters CA, Wein AJ, Campbell-Waish Urology 11th Ed, Saunders Elsevier, Philadelphia, pp.126-132.
Thakar C, 2012, Postoperative Kidney Injur, in Grant P \& Jaffer A, Perioperative Medicine : Medical Consultation and Co-Management, Willey-BlackWell, New Jersey, pp.499-515.

Thakar C, 2011, Perioperative Acute Kidney Injury, in Thakar C, Advances in Chronic Kidney Disease, Elsevier Inc, Cincinnati, pp.67-75.

Wagener G \& Brentjens T, 2010. Anesthetics Concern in Patients Presenting with Renal Failure. Anesthesiology Clin, 28:39-54.

Webb S \& Allen J, 2008. Perioperative Renal Protection. British Journal of Anesthesia, 8(5)176-180.

Whinney C, 2012, Perioperative Medication Management, in Grant P \& Jaffer A, Perioperative Medicine : Medical Consultation and Co-Management, Willey-BlackWell, New Jersey, pp.47-62.

Zarbock A, Koyner J, Hoste E \& Kellum J, 2018. Update on Perioperative Acute Kidney Injury. International Anesthesia Research Society, 30(30)1-10.

Zura M \& Sakic L, 2013. Regional Anesthesia and Chronic Renal Disease. Periodicum Biologorum, 115(2)271:273. 